\title{
Outcome of middle cerebral artery territory stroke without recanalization therapy in a tertiary care hospital of Bangladesh
}

\author{
Subash Kanti Dey, Md Shahidullah, Anis Ahmed, Md Ahsan Habib, Mst Habiba Khatun, Abu Nasir \\ Rizvi, Ashish Chowdhury
}

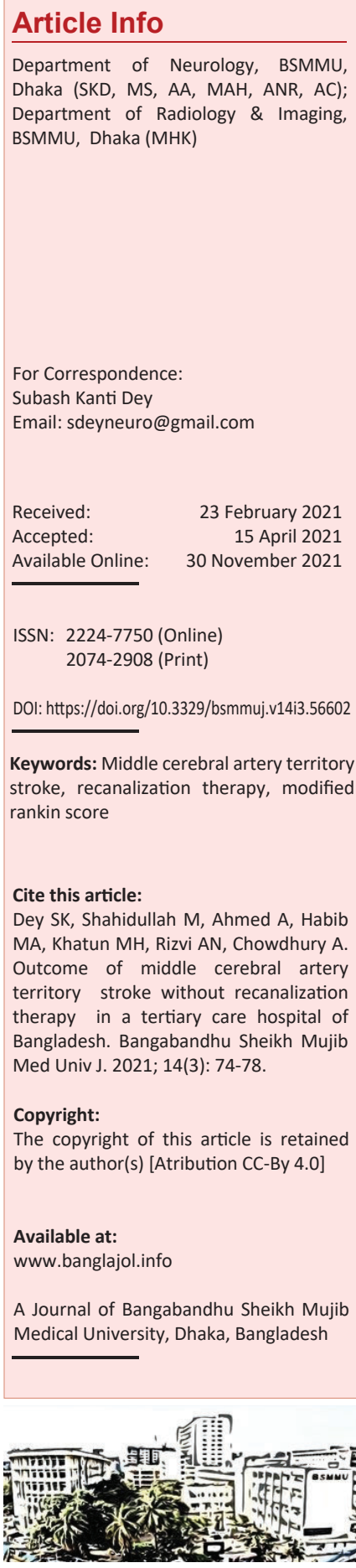

\section{Abstract}

Among all the large vessel territory stroke, middle cerebral artery (MCA) territory stroke is the most common . Outcome depends on awareness and availability of specific treatment and proper conservative management after stroke. This prospective cohort study enrolled 49 clinically and radiologically diagnosed MCA territory stroke patients admitted in Neurology Department of Bangabandhu Sheikh Mujib Medical University (BSMMU) from January 2018 to December 2020. The aim was to see the prognosis of the middle cerebral artery territory (MCA) stroke patient who were treated conservatively. The Modified Rankin Scale (mRS) was used to measure the prognosis just after admission, after three months, six months, one year and two years; and the mean scores were $3.88 \pm 0.88,3.33 \pm 1.24,2.98 \pm 1.42,2.67 \pm 1.60$ \& $2.23 \pm 1.56$ respectively. Among 49 patients, 9 patients died over the study period; one patient within one month after stroke, 3 patients within 3 months and 5 patients within six months. Though death rate was high in first three months, the survived patients improved significantly with conservative management in next two years of follow-up period.

\section{Introduction}

Large territory middle cerebral artery strokes are devastating events that result in high rates of disability and death. Nearly half of all stroke survivors never regain functional independence. ${ }^{1}$ Intravenous recombinant tissue plasminogen activator (IV-rtPA) i.e. Alteplase is approved for the treatment of acute ischaemic stroke. Previous analyses of pooled data from randomised trials concluded that Alteplase is beneficial when administered to some patients within $4.5 \mathrm{~h}$, but that the magnitude of benefit diminishes with increasing treatment delay. ${ }^{2,3}$ The combined treatment with stent retriever mechanical thrombectomy (MT) devices and IV-rtPA within 6 hours after stroke onset is superior to standard medical therapy (with IV-rtPA alone) for acute ischemic stroke caused by a proximal large artery occlusion of the anterior circulation. ${ }^{4}$

Many studies that involved thrombolytic therapy showed that severe stroke was associated with symptomatic intracerebral hemorrhage and is inversely related to a favorable outcome. ${ }^{5-8}$ Intravenous rtPA is able to recanalize in approximate $1 / 3$ of the patients. ${ }^{9}$ This may explain the limited efficacy in these patients. Studies revealed that combination of rapid endovascular therapy and intravenous thrombolysis showed increased rate of recanalization and the improvement of clinical outcomes in patients with acute stroke from major artery occlusion. ${ }^{10-12}$ However, endovascular treatment requires more organized system of stroke care, health care personnel with special expertise and available interventionists. Advanced neuroimaging capabilities, including cerebral angiography, which are available in only comprehensive stroke center are also required. Bangladesh is a developing country. Due to lack of awareness and availability of the specific treatment, most of the patients can not avail the treatment. These patients are usually treated conservatively.

There are many scales to measure the disability after stroke. The Modified Rankin 
Scale (mRS) is commonly used to measure the degree of disability in patients who have had a stroke. ${ }^{16-18}$ The score ranges from 0-6. Score 0-2 is categorized as good outcome. Score 6 is scored as death from stoke.

The aim of the study was to see the prognosis of the middle cerebral artery territory (MCA) stroke patients who were treated conservatively.

\section{Methods}

This prospective cohort study enrolled 49 stroke patients admitted in Neurology department of Bangabandhu Sheikh Mujib Medical University (BSMMU) from January 2018 to December 2020. After history taking and clinical examination, Computed tomography (CT) scan of brain was done. After confirming ischemic stroke, Magnetic resonance angiography (MRA) or computed tomography angiography (CTA) of brain and neck was done to identify \& confirm occluded vessels. Other vascular territory stroke except MCA territory were excluded from the study. Emergency management of stroke was done and co-morbidities were treated properly. Patients who survived acute attack were followed-up at three months, six months, one year and two years to see the outcome. Patients were assessed with Modified Rankin Scale (mRS) just after admission, at three months, six months, one year and after two years to assess the improvement or deterioration. Data were also analyzed regarding demographic information \& risk factors.

\section{Results}

Total 49 ischemic stroke patient clinically and radiologically confirmed as MCA territory stroke and who could not avail the recanalization therapy were enrolled.

Mean age of the patient was $58.65 \pm 10.60$ years. Most frequent age group was $50-60$ years, which was $34.7 \%$. (Table - I)

\section{Table I}

Distribution of the patients according to age $(n=49)$

\begin{tabular}{|l|c|c|}
\hline Age (years) & Frequency & Percentage \\
\hline$\leq 50$ & 12 & 24.4 \\
\hline $50-60$ & 17 & 34.7 \\
\hline $60-70$ & 15 & 30.6 \\
\hline$>70$ & 5 & 10.2 \\
\hline
\end{tabular}

Pie chart shows male are predominantly affected which was $61.2 \%$. Female were $38.8 \%$. (Figure -1 )

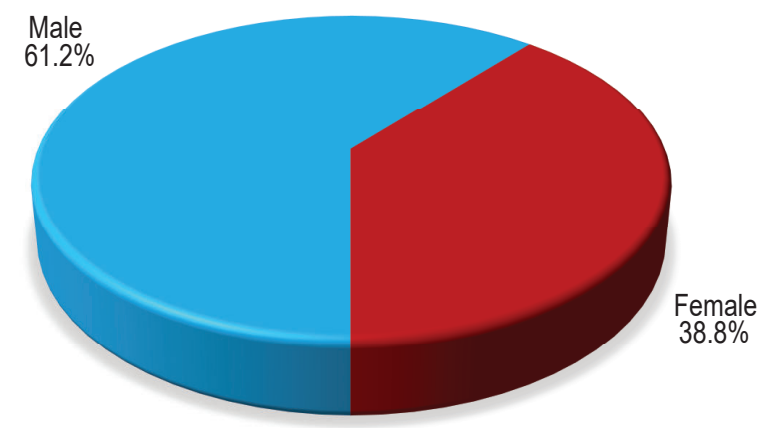

Figure 1: Pie chart of the patients according to sex

Most of the patients were leading sedentary life style. which was about $85.7 \%$. Hypertension was present in $73.5 \%$ patients, dyslipidemia was $71.4 \%$. (Table-II).

\section{Table-II}

\begin{tabular}{|l|c|c|}
\multicolumn{2}{|c|}{ Distribution of the patients according to risk factors } \\
Rin=49) \\
Risk factors & Frequency & Percent \\
\hline Life style & & \\
\hline o Sedentary & 42 & 85.7 \\
\hline o Active & 7 & 14.3 \\
\hline HTN & 36 & 73.5 \\
\hline DM & 24 & 49.0 \\
\hline IHD & 5 & 10.2 \\
\hline Arrhythmia & 5 & 10.2 \\
\hline Smoking & 18 & 36.7 \\
\hline Dyslipidaemia & 35 & 71.4 \\
\hline Family history & 20 & 40.8 \\
\hline OCP taking & 8 & 42.1 \\
\hline
\end{tabular}

Patients with left sided MCA territory stroke had also significant carotid stenosis in $85.7 \%$ patients. Comparison of carotid stenosis between right and left MCA was not significant ( $\mathrm{p}$ value $>0.05)$. (Table - III) 


\begin{tabular}{|c|c|c|c|c|}
\hline \multicolumn{5}{|c|}{ Table III } \\
\hline \multicolumn{5}{|c|}{$\begin{array}{l}\text { Distribution of the patients according to status of } \\
\text { extracranial carotid stenosis by side of MCA stenosis }(n=49)\end{array}$} \\
\hline \multirow{2}{*}{$\begin{array}{l}\text { Status of extra- } \\
\text { cranial carotid }\end{array}$} & \multirow[t]{2}{*}{ Total } & \multicolumn{2}{|c|}{ Side of MCA stenosis } & \multirow{2}{*}{$\underset{\text { value }^{*}}{p}$} \\
\hline & & Right & Left & \\
\hline Nil & $28(57.1)$ & $12(42.9)$ & $16(57.1)$ & \\
\hline$<50 \%$ & $10(20.4)$ & $7(70.0)$ & $3(30.0)$ & \\
\hline $50-69 \%$ & 7 (14.3) & $1(14.3)$ & $6(85.7)$ & 0.108 \\
\hline $70-99 \%$ & $2(4.1)$ & $1(50.0)$ & $1(50.0)$ & \\
\hline $\begin{array}{l}\text { Complete } \\
\text { occlusion }\end{array}$ & $2(4.1)$ & $2(100.0)$ & $0(.0)$ & \\
\hline Total & $49(100.0)$ & $23(46.9)$ & $26(53.1)$ & \\
\hline
\end{tabular}

${ }^{*}$ Chi-square test was done to measure the level of significance. Figure within parenthesis indicates in percentage.

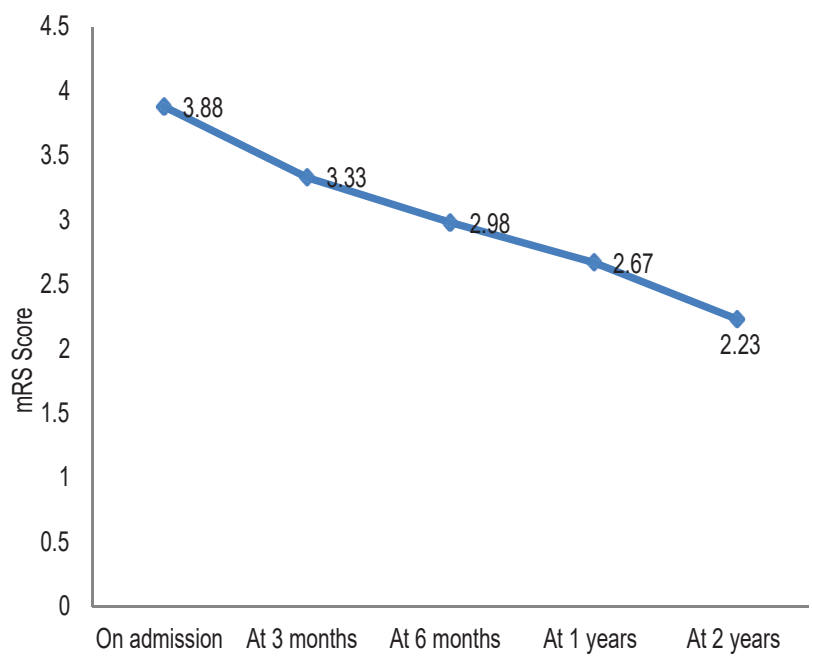

Figure 2 : Line chart of the patients according to status of mRS in different follow up

Table IV

Distribution of the patients according to status of mRS in different follow up

\begin{tabular}{|c|c|c|c|c|c|}
\hline mRS score & $\begin{array}{l}\text { On admission } \\
\quad(n=49)\end{array}$ & $\begin{array}{l}\text { At } 3 \text { months } \\
\quad(n=48)\end{array}$ & $\begin{array}{l}\text { At } 6 \text { months } \\
\quad(n=45)\end{array}$ & $\begin{array}{l}\text { At } 1 \text { years } \\
(n=42)\end{array}$ & $\begin{array}{c}\text { At } 2 \text { years } \\
(n=40)\end{array}$ \\
\hline 0 & - & - & $1(2.0)$ & $1(2.4)$ & $4(10.0)$ \\
\hline 1 & - & $1(2.1)$ & - & $8(19.0)$ & $10(25.0)$ \\
\hline 2 & $2(4.1)$ & $11(22.9)$ & $23(46.9)$ & 18 (42.9) & $14(35.0)$ \\
\hline 3 & $15(30.6)$ & $21(43.8)$ & 9 (18.4) & $4(9.5)$ & $4(10.0)$ \\
\hline 4 & $20(40.8)$ & $4(8.3)$ & $2(4.1)$ & $1(2.4)$ & $1(2.5)$ \\
\hline 5 & $11(22.4)$ & $8(16.7)$ & 7 (14.3) & $8(19.0)$ & 7 (17.5) \\
\hline Death & $1(2.0)$ & $3(6.2)$ & $3(6.1)$ & $2(4.8)$ & - \\
\hline Mean \pm SD & $3.88 \pm 0.88$ & $3.33 \pm 1.24$ & $2.98 \pm 1.42$ & $2.67 \pm 1.60$ & $2.23 \pm 1.56$ \\
\hline p value* & - & 0.002 & 0.001 & $<0.001$ & $<0.001$ \\
\hline
\end{tabular}

${ }^{*} \mathrm{p}$ value was done by Paired $\mathrm{t}$ test and compared with on admission.

Figure within parenthesis indicates in percentage.

On admission mean mRS was $3.88 \pm 0.88$. The mean scores were $3.33 \pm 1.24,2.98 \pm 1.42,2.67 \pm 1.60 \& 2.23 \pm 1.56$ at 3 months, 6 months, one years and two years respectively. After 3 months, 6 months, one year and after two years, p values were $0.002,0.001,<0.001,<0.001$ respectively which were statistically significant ( $\mathrm{p}$ value $<0.05$ ) (Table-IV, Figure-2)

\section{Discussion}

In this study mean age of the MCA territory stroke was 58.65 \pm 10.60 (25-80) years. Kim et al showed that mean age was $61 \pm 14 .{ }^{16}$ Male were more sufferer than female which is similar to previous study. ${ }^{17}$

In this study most of the patients were leading sedentary life style. which was about $85.7 \%$. Hypertension was present in 
$73.5 \%$ patients, dyslipidaemia was $71.4 \%$. In another study, hypertension was $72.5 \%$, DM $35.6 \%$, dyslipidaemia $48.3 \%{ }^{18}$

Patients with Left sided MCA territory stroke had also significant carotid stenosis in $85.7 \%$ patients. Association of carotid stenosis between right and left MCA artery stroke was not significant. On admission mean $\mathrm{mRS}$ was $3.88 \pm 0.88$. To assess the prognosis, mRS was recalculated at 3 months, 6 months, one years and two years and it was $3.33 \pm 1.24,2.98 \pm$ $1.42,2.67 \pm 1.60,2.23 \pm 1.56$ respectively.

Within one month, death rate was $2 \%$, but within 3 months it was increased to $6.2 \%$. In a study involving 1287 patients of MCA stroke (634 assigned to endovascular thrombectomy, 653 assigned to control), endovascular thrombectomy led to significantly reduced disability at 90 days compared with control (adjusted OR 2.49, 95\% CI 1.76-3.53; p<0.0001). ${ }^{19}$ In this study without any endovascular thrombectomy, disability also reduced by conservative management ( $\mathrm{p}$ value $=0.002)$. A review of 10 randomised controled trial $(n=2925)$ revealed that, endovascular treatment, including thrombectomy was associated with a higher proportion of patients experiencing good (modified Rankin scale scores $\leq 2$ ) and excellent (scores $\leq 1$ ) outcomes 90 days after stroke. There was no difference in mortality or rate of symptomatic intracranial haemorrhage, compared with patients randomised to medical care alone, including intravenous rt-PA. ${ }^{20} 46$ (87\%) of 53 patients treated with the IV-endovascular approach achieved recanalisation versus 56 (52\%) of 107 patients in the IV group (adjusted relative risk [RR] 1.49, 95\% CI 1.21-1.84; p=0.0002). Early neurological improvement (NIHSS score of 0 or 1 or an improvement of 4 points or more at $24 \mathrm{~h})$ occurred in $32(60 \%)$ patients in the IV-endovascular group and $42(39 \%)$ patients in the IV group (adjusted RR 1.36, 0.97-1.91; $\mathrm{p}=0.07$ ). Favourable outcome (mRS of $0-2$ at 90 days) occurred in 30 (57\%) patients in the IV-endovascular group and $47(44 \%)$ patients in the IV group (adjusted RR 1.16, 0.85-1.58; $\mathrm{p}=0.35$ ). The mortality rate at 90 days was $17 \%$ in both groups, and symptomatic intracranial haemorrhage was reported in five $(9 \%)$ patients in the IV-endovascular group and in $12(11 \%)$ patients in the IV group. Better clinical outcome was associated with recanalisation in both groups and with time to recanalisation in the IV-endovascular group. ${ }^{21}$

According to 53 studies encompassing 2066 patients, reported recanalization rates were - spontaneous $(24.1 \%)$, intravenous fibrinolytic (46.2\%), intra-arterial fibrinolytic (63.2\%), combined intravenous-intra-arterial (67.5\%), and mechanical (83.6\%). Clinical outcome data categorized by success or failure in achieving recanalization was available from 33 articles encompassing 998 patients. Good functional outcomes at 3 months were more frequent in recanalized versus nonrecanalized patients with odds ratio of 4.43 (95\% CI, 3.32 to 5.91). Three-month mortality was reduced in recanalized patients (odds ratio, $0.24 ; 95 \% \mathrm{CI}, 0.16$ to 0.35 ). Rates of symptomatic hemorrhagic transformation did not differ between the 2 groups (odds ratio, 1.11; 95\% CI, 0.71 to 1.74 ). ${ }^{22}$

In this study mRS was also measured after 6 months ( $P$ value 0.001 ) after one year ( $P$ value $<0.001$ ) and after two years ( $P$ value $<0.001)$

\section{Conclusion}

Though death rate is very high in first three months after MCA stroke, disability of MCA stroke survivors significantly improved with conservative management.

Conflict of interest: Author has no conflict of interest.

\section{References}

1. Roger VL, Go AS, Lloyd-Jones DM, Adams RJ, Berry JD, Brown TM et al. Heart Disease and Stroke Statistics - 2011 Update. Circulation. 2011;123(4) : e18-e209.

2. Association of outcome with early stroke treatment: pooled analysis of ATLANTIS, ECASS, and NINDS rt-PA stroke trials. The Lancet. 2004;363(9411):768-74.

3. Lees KR, Bluhmki E, von Kummer et al. Time to treatment with intravenous alteplase and outcome in stroke: an updated pooled analysis of ECASS, ATLANTIS, NINDS, and EPITHET trials. Lancet. 2010; 375: 1695-1703

4. Berkhemer OA, Majoie CB, Dippel DW. Endovascular therapy for ischemic stroke. NEJM. 2015;372(24): 2363

5. Wahlgren N, Ahmed N, Eriksson N, Aichner F, Bluhmki E, Dávalos A, et al. Multivariable analysis of outcome predictors and adjustment of main outcome results to baseline data profile in randomized controlled trials: Safe implementation of thrombolysis in stroke-monitoring study (SITS-MOST) Stroke. 2008;39:3316-22.

6. Demchuk AM, Tanne D, Hill MD, Kasner SE, Hanson S, Grond $\mathrm{M}$, et al. Predictors of good outcome after intravenous tPA for acute ischemic stroke. Neurology. 2001;57:474-80.

7. Dharmasaroja PA, Dharmasaroja P, Muengtaweepongsa S. Outcomes of Thai patients with acute ischemic stroke after intravenous thrombolysis. J Neurol Sci. 2011;300:74-7.

8. Dharmasaroja PA, Muengtaweepongsa S, Pattaraarchachai J, Dharmasaroja P. Intracerebral hemorrhage following intravenous thrombolysis in Thai patients with acute ischemic stroke. J Clin Neurosci. 2012;19:799-803.

9. Christou I, Burgin WS, Alexandrov AV, Grotta JC. Arterial 
status after intravenous TPA therapy for ischaemic stroke. A need for further interventions. Int Angiol. 2001; 20:208-13.

10. Berkhemer OA, Franse PS, Beumer D, Yeatts SD, Khatri P, Hill $\mathrm{MD}$, et al. A randomized trial of intra-arterial treatment for acute ischemic stroke. $\mathrm{N}$ Engl J Med. 2015;372:11-20.

11. Goyal M, Demchuk AM, Menon BK, Sqoifo A, Ponsio M, Sterzi R, et al. Randomized assessment of rapid endovascular treatment of ischemic stroke. N Engl J Med. 2015;372:1019-30.

12. Campbell BC, Mitchell PJ, Kleinig TJ, Dewey HM, Churilov L, Yassi $\mathrm{N}$ et al. Endovascular therapy for ischemic stroke with perfusion-imaging selection. N Engl J Med. 2015;372:1009-18.

13. Rankin J. Cerebral vascular accidents in patients over the age of 60. Scott Med J. 1957;2:200-15

14. Bonita R, Beaglehole R. Modification of Rankin Scale: Recovery of motor function after stroke. Stroke 1988 Dec;19(12):1497-1500

15. Van Swieten JC, Koudstaal PJ, Visser MC, Schouten HJ, van Gijn J. Interobserver agreement for the assessment of handicap in stroke patients. Stroke 1988;19(5):604-7

16. Kim JS, Nah H-W, Park SM, Kim S-K, Cho KH, Lee J, et al. Risk Factors and Stroke Mechanisms in Atherosclerotic Stroke. Stroke. 2012;43(12):3313-8.
17. Dharmasaroja PA, Muengtaweepongsa S. Outcomes of patients with large middle cerebral artery infarct treated with and without intravenous thrombolysis. Journal of Neurosciences in Rural Practice. 2016;7(01):36-9.

18. Goyal M, Memon B, Zwam WH, Dippel DW, Mitchell PJ, Demchuk AM et al. Endovascular thrombectomy after large-vessel ischaemic stroke: a meta-analysis of individual patient data from five randomised trials. Lancet. 2016 Apr 23;387(10029):1723-31.

19. Rodrigues F B, Neves J B, Caldeira D, Ferro JM, Ferreira J et al. Endovascular treatment versus medical care alone for ischaemic stroke: systematic review and meta-analysis. BMJ. 2016; 18;353:1754.

20. Mazighi M, Serfaty JM, Labreuche J. Comparison of intravenous alteplase with a combined intravenousendovascular approach in patients with stroke and confirmed arterial occlusion (RECANALISE study): a prospective cohort study. Lancet Neurol.9 2009;8:802-9.

21. Mattle HP, Arnold M, Georgiadis D, Baumann C, Nedeltchev. Comparison of Intraarterial and Intravenous Thrombolysis for Ischemic Stroke With Hyperdense Middle Cerebral Artery Sign. Stroke. 2008; 39(2), 379-83.

22. Rha J H, Saver J L . The Impact of Recanalization on Ischemic StrokeStroke. 2007;38:967-73. 